\title{
Photocatalytic transformation of organic compounds in the presence of inorganic ions*
}

\author{
Paola Calza and Ezio Pelizzetti ${ }^{\ddagger}$ \\ Dipartimento di Chimica Analitica, Università di Torino, via P. Giuria 5, 10125 \\ Torino, Italy
}

\begin{abstract}
The influence of halide ions on the photocatalytic process on titanium dioxide has been investigated carefully. Chloride and bromide ions, acting as hole scavengers, generate active radical species (e.g., $\cdot \mathrm{Cl}$ and $\cdot \mathrm{Br}$ ) that participate in reactions with the organic compounds and the transient intermediates. Chloride and bromide ions have shown to deeply inhibit the degradation rate of chloroform and tetrachloromethane and to modify both the qualitative and quantitative distribution of their intermediates formed during the degradation process. In the presence of bromide, $\mathrm{CBrCl}_{3}$ is detected as intermediate during $\mathrm{CCl}_{4}$ degradation, while in the presence of chloride, formation of $\mathrm{CCl}_{4}$ is observed in the $\mathrm{CHCl}_{3}$ degradation. Fluoride ions, differently from the other halides, cannot be oxidized by the valence hole and may be used as a diagnostic tool in mechanistic studies. The influence of fluoride on phenol has been investigated, and, by choosing appropriate experimental conditions, it was possible to evaluate the role of the different active species in the photocatalytic process.
\end{abstract}

\section{INTRODUCTION}

Photocatalytic oxidation of organic molecules in aqueous aerated suspensions leads in almost all cases and through a sequence of reactions to the stoichiometric formation of carbon dioxide and, eventually, to inorganic ions. Besides, reductive photocatalytically induced processes are responsible for the degradation of halogenated compounds as tetrachloromethane.

However, the presence of inorganic ions has been shown to influence the kinetics and mechanism of the transformation processes of organic compounds. It is well known that the photocatalytic reactions occur at the surface of the semiconductor particle [1], so that specific adsorption of ions may affect the system performance. Specific adsorption of ions can give surficial coordination reactions at the oxide-water interface [2]. The adsorption degree is dependent on the value of $\mathrm{pH}$ and on the exchange reactions with the surface hydroxyl groups. The surface occupation by anions may be competitive with the adsorption of organic molecules, this effect being directly related to their coverage fraction.

Inhibition by strongly adsorbed anions has been reported, while for weakly adsorbed anions such as nitrate and perchlorate, a negligible effect has been observed [3-5]. In this paper, the effect of halides (chloride, bromide) on chloromethanes and of fluoride on phenol will be considered. The purpose of this investigation was to get information on the effect of these anions on the photocatalytic pathways of organic transformations and the extent of inhibition as a function of the nature of the anions. In particular, the $\mathrm{TiO}_{2} / \mathrm{F}$ system may be used as a diagnostic tool in describing the role of active species involved in oxidation processes.

\footnotetext{
*An issue of reviews and research papers based on presentations made at the IUPAC/ICSU Workshop on Electrochemistry and Interfacial Chemistry in Environmental Clean-up and Green Chemical Processes, Coimbra, Portugal, 6-7 April, 2001.

${ }^{\ddagger}$ Corresponding author: Fax: 39-011-6707615; E-mail: pelizzet@ch.unito.it
} 


\section{EXPERIMENTAL CONDITIONS}

\section{Materials and reagents}

Dichloromethane (Aldrich), chloroform (Aldrich), tetrachloromethane (Aldrich), and phenol (Aldrich) were used as received for all the tests. Experiments were carried out using $\mathrm{TiO}_{2}$ Degussa P25 (surface area $50 \mathrm{~m}^{2} \mathrm{~g}^{-1}$ ). In order to avoid possible interference from ions adsorbed on the photocatalyst, the $\mathrm{TiO}_{2}$ Degussa P25 powder was irradiated and washed with double distilled water until no signal due to chloride, sulphate, or sodium ions could be detected by ion chromatography. $\mathrm{HClO}_{4}, \mathrm{HNO}_{3}$, and $\mathrm{NaOH}$ (reagent grade) were used to adjust the $\mathrm{pH}$.

\section{Irradiation procedures}

The irradiation was carried out on suspensions containing $\mathrm{TiO}_{2}$ and the organic compound. The irradiation experiments have been carried out in Pyrex glass cells (cut-off at $295 \mathrm{~nm}, 4.0 \mathrm{~cm}$ diameter, $2.3 \mathrm{~cm}$ height), containing $5 \mathrm{ml}$ of the aqueous suspension of the photocatalyst powder and substrate, using a $1500 \mathrm{~W}$ xenon lamp (CO.FO.MEGRA, Milan, Italy) equipped with a cut-off filter of $340 \mathrm{~nm}$. Total photon flux entering in the irradiation cell was $8.1 \times 10^{19}$ quanta $\mathrm{sec}^{-1} \mathrm{~m}^{-2}$, as determined by ferrioxalate actinometry.

The cell temperature during irradiation was $50{ }^{\circ} \mathrm{C}$. The suspension homogeneity, as well as good oxygen exchange with the gaseous phase (air) contained in the cell, is assured by magnetic stirring.

\section{Analytical procedures}

The cooled sample (around $5{ }^{\circ} \mathrm{C}$ ) was preliminarily filtered through $0.45 \mu \mathrm{m}$ cellulose acetate membranes (Millipore HA). The entire content of the cell was analyzed for dichloromethane, chloroform, and tetrachloromethane after the established irradiation time by Purge and Trap/GC. A purge-and-trap system (Tekmar LSC 2000) with criofocusing connected to a gas-chromatograph (Varian STAR 3400) equipped with 1 FID detector and $60 \mathrm{~m}$ DB5 column (Supelco, $0.25 \mu \mathrm{m}$ coating) was used. The samples were analyzed after proper dilution directly into $P \& G$ vessel (10-100 $\mu \mathrm{L}$ to $5 \mathrm{ml}$ ). The Purge and Trap's operative parameters were: standby $35^{\circ} \mathrm{C}$, purge $15 \mathrm{~min}$, dry purge $3 \mathrm{~min}$., desorb preheat $255^{\circ} \mathrm{C}$, desorb at 260 for $3 \mathrm{~min}$, cryo cool down at $-100{ }^{\circ} \mathrm{C}$, inject at $220^{\circ} \mathrm{C}$, and bake at $250{ }^{\circ} \mathrm{C}$ for $7 \mathrm{~min}$. The analyses were performed using a double gradient; temperature was linearly increased at $12{ }^{\circ} \mathrm{C} / \mathrm{min}$ from 37 to $157^{\circ} \mathrm{C}$ and then was brought to $300{ }^{\circ} \mathrm{C}$ at a rate of $30{ }^{\circ} \mathrm{C} / \mathrm{min}$. Phenol and dihydroxybenzenes were detected by HPLC using a Rheodyne 7125 injector, an RP C18 column (Lichrochart, Merck $12.5 \times 0.4 \mathrm{~cm}$ ), and a UV-vis detector (Merck Hitachi L-4200).

Total organic carbon (TOC) was measured on filtered suspensions using a Shimadzu TOC-5000 analyzer (catalytic oxidation on Pt at $680^{\circ} \mathrm{C}$ ). Calibration was achieved by injecting standards of potassium phthalate.

The formation of chloride and bromide ions was monitored by suppressed ion chromatography, using a Biotronik IC 5000 apparatus with a BT1AN separation column (20 cm length, $4 \mathrm{~mm}$ 1.d., Biotronik) and an alkaline buffer eluant containing $\mathrm{NaHCO}_{3}(3 \mathrm{mM})$ at the flow rate of $1.5 \mathrm{~mL} \mathrm{~min}^{-1}$. Under these conditions, the retention time of chloride and bromide ions were $4.3 \mathrm{~min}$ and $5.5 \mathrm{~min}$, respectively.

\section{DISCUSSION}

\section{Interaction of inorganic ions at the oxide surface}

If it is assumed that the chemicals events occur predominantly at the surface, only those ions that are bound to $\mathrm{TiO}_{2}$ or are very close to its surface can have significant effects. Consequently, the point of zero charge (PZC) should be a determining property; for $\mathrm{TiO}_{2}$ Degussa $\mathrm{P} 25$, the $\mathrm{pH}_{\mathrm{PZC}}$ is 6.3 [6]. 
The two surfacial acid-basic equilibria are:

$\mathrm{TiOH}_{2}^{+} \leftrightarrow \mathrm{TiOH}+\mathrm{H}^{+}$

$\mathrm{TiOH} \leftrightarrow \mathrm{TiO}^{-}+\mathrm{H}^{+}$

At $\mathrm{pH}>\mathrm{pH}_{\mathrm{PZC}}$, several anions, such as chloride, sulphate, and nitrate have been found to have no effect on the initial rate of disappearance of 3-chlorophenol [5] and phenol [7]. Since at $\mathrm{pH}>\mathrm{pH}_{\mathrm{PZC}}$, the surface is negatively charge (see equilibrium 2), the concentration in anions is lower near the $\mathrm{TiO}_{2}$ surface than in the bulk of the solution [8].

In the literature studies at $\mathrm{pH}<\mathrm{pH}_{\mathrm{PZC}}$, including the effect of $\mathrm{Cl}^{-}, \mathrm{SO}_{4}{ }^{2-}$, and $\mathrm{NO}_{3}{ }^{-}[5], \mathrm{H}_{2} \mathrm{PO}_{4}^{-}$ and $\mathrm{ClO}_{4}^{-}$[9] on several organic compounds, such as 3-chlorophenol [5], salicylic acid, aniline, and ethanol [9] are also available. No effect of nitrate and perchlorate was observed, while chloride, sulfate, and phosphate have detrimental effect.

At $\mathrm{pH}<\mathrm{PZC}$, the surface is positively charged as is expressed by eq. 1 . The concentration of monovalent anions at the surface, $\left[\mathrm{A}^{-}\right]_{\mathrm{S}}$, is linked to the concentration in the bulk $\left[\mathrm{A}^{-}\right]_{\mathrm{b}}$ and to the surface charge $\sigma[8]$, according to eq. 3 :

$$
\left[\mathrm{A}^{-}\right]_{\mathrm{S}}=\sigma / 2 \varepsilon \varepsilon_{0} \mathrm{KT}+2\left[\mathrm{~A}^{-}\right]_{\mathrm{b}}
$$

Although this coulombic treatment shows a marked excess of anions close to the surface, it does not predict differences between the various monovalent anions considered [10]. The contrasting effects of the anions at the acidic $\mathrm{pH}$ indicate either a competition between the inorganic salt and the organic compound for the surface oxidizing species (holes, $\mathrm{OH}$ radicals) and/or a competitive adsorption. In the latter case, as in the case of chloride, the Langmuir-Hinshelwood kinetic model would indicate that the reciprocal of the initial rate, $\mathrm{r}_{0}$, of disappearance of the organic substrate increases linearly with the concentration of anion. However, the Langmuir-Hinshelwood model is not compatible with the fact that the surface concentration of chloride ions does not depend much on the bulk concentration if only electrostatic forced is taken into account. Then, the participation of halides in the photocatalytic process will the discussed below.

\section{PHOTOCATALYTIC PROCESS}

$\mathrm{TiO}_{2}$ photoactivity is due to the adsorption of UV light (of energies with $\lambda<380 \mathrm{~nm}$ ) that generates active species (electron/holes pairs) in the bulk of the semiconductor (reaction 4). Heterogeneous photocatalysis occurs over semiconductor oxides in which the charge carriers are ultimately positioned at the particle surface to undergo a variety of events (recombination, trapping) in competition with the redox chemistry involving solubilizate and solvent molecules.

The photogenerated pairs can recombine according to reactions 6 and 7 or be trapped at the surface (reaction 5). If electron acceptors $\left(\mathrm{Ox}_{1}\right)$ or electron donors $\left(\operatorname{Red}_{1}, \mathrm{H}_{2} \mathrm{O}\right)$ are present at the surface, interfacial electron transfers may occur according to reactions $8-14$. The overall reactions involved are reported below.

Charge separation

Surface trapping

Recombination

Interfacial charge transfer

$$
\begin{aligned}
& \mathrm{TiO}_{2}+\mathrm{h} v \rightarrow \mathrm{e}_{\mathrm{CB}}^{-}+\mathrm{h}^{+} \mathrm{VB}^{+} \\
& \mathrm{h}^{+}{ }_{\mathrm{VB}}+\equiv \mathrm{TiOH} \rightarrow \equiv \mathrm{TiO} \cdot+\mathrm{H}^{+} \\
& \mathrm{e}^{-}{ }_{\mathrm{CB}}+\mathrm{h}^{+}{ }_{\mathrm{VB}} \rightarrow \text { heat } \\
& \mathrm{e}^{-} \mathrm{CB}+\equiv \mathrm{TiO} \cdot+\mathrm{H}^{+} \rightarrow \equiv \mathrm{TiOH} \\
& \mathrm{h}^{+}{ }_{\mathrm{VB}}+\operatorname{Red}_{1} \rightarrow \mathrm{Ox} \\
& \equiv \mathrm{TiO}+\operatorname{Red}_{1} \rightarrow \mathrm{Ox}^{\prime}
\end{aligned}
$$


Back reactions

$$
\begin{aligned}
& \mathrm{h}^{+}{ }_{\mathrm{VB}}+\mathrm{H}_{2} \mathrm{O} \rightarrow \mathrm{H}_{2} \mathrm{O}^{+} \\
& \mathrm{H}_{2} \mathrm{O}^{+} \rightarrow \mathrm{H}^{+}+\mathrm{OH} \cdot \\
& \mathrm{OH} \cdot+\equiv \mathrm{TiOH} \rightarrow \equiv \mathrm{TiO} \cdot+\mathrm{H}_{2} \mathrm{O} \\
& \mathrm{OH} \cdot+\operatorname{Red}_{1} \rightarrow \mathrm{Ox}^{\prime \prime} \\
& \mathrm{e}_{\mathrm{CB}}^{-}+\mathrm{Ox}_{1} \rightarrow \mathrm{Red}_{2}
\end{aligned}
$$

In aerated systems, oxygen acts as an efficient electron scavenger in reaction 14:

Oxygen reactions

$$
\left.\mathrm{O}_{2}(\text { ads })+\mathrm{e}^{-}{ }_{\mathrm{CB}} \rightarrow \mathrm{O}_{2} \cdot{ }^{-}{ }^{-} \text {ads }\right)
$$

If halides $\left(\mathrm{X}^{-}\right)$are present, some more reactions can occur. The primary events occurring at the catalyst surface in the presence of an anion $\mathrm{X}^{-}$may be summarized as follows:

Surface complex

Surface trapping

Interfacial charge transfer

Halide oxidation

Recombination

Back reaction

$$
\begin{aligned}
& \equiv \mathrm{TiOH}+\mathrm{X}^{-} \rightarrow \equiv \mathrm{TiX}+\mathrm{OH}^{-} \\
& \mathrm{h}^{+}{ }_{\mathrm{VB}}+\equiv \mathrm{TiX} \rightarrow \equiv \mathrm{TiX}^{+} \\
& \equiv \mathrm{TiX}^{+}+\operatorname{Red}_{1} \rightarrow \mathrm{Ox}_{1}{ }^{\prime \prime} \\
& \mathrm{h}^{+}{ }_{\mathrm{VB}}+\mathrm{X}^{-} \rightarrow \mathrm{X} \cdot \\
& \mathrm{e}^{-}{ }_{\mathrm{CB}}+\equiv \mathrm{TiX}^{+} \rightarrow \equiv \mathrm{TiX} \\
& \mathrm{e}^{-}{ }_{\mathrm{CB}}+\mathrm{X} \cdot \rightarrow \mathrm{X}^{-} \\
& \equiv \mathrm{TiX}^{+}+\operatorname{Red}_{2} \rightarrow \equiv \mathrm{TiX}
\end{aligned}
$$

\section{Effect of halides on the photocatalytic transformation of organic compounds}

Some of the halides (chloride, bromide, and iodide) can be thermodynamically oxidized by valence band holes, thus acting as hole scavenging. At $\mathrm{pH} \mathrm{5,} \mathrm{the} \mathrm{titania} \mathrm{valence} \mathrm{band} \mathrm{hole} \mathrm{is} \mathrm{able} \mathrm{to} \mathrm{oxidize}$ chloride ions to chlorine radical according to reaction 21 [11-13], for which the standard reduction potential is $\mathrm{E}_{0}=+2.5 \mathrm{~V}$ [14], and bromide to bromine radical $\left(\mathrm{E}_{0}=2.0 \mathrm{~V}\right)$. However, the formed radical could back-react with conduction band electrons, according to reaction 20 . This gives a null process, which lowers the concentration of available holes and electrons. The radical species X-can attack the organic compound through an addition/elimination reaction with a specific rate constant lower of radicals.

Fluoride anion shows strong adsorption on $\mathrm{TiO}_{2}$ [15]. The estimated redox potential of the couple $\cdot \mathrm{F} / \mathrm{F}^{-}$is $3.6 \mathrm{~V}$ [16], which makes fluoride stable against oxidation by $\mathrm{TiO}_{2}$ valence holes, even in acidic media. Thus, for this anion, the redox competition with the organics is not possible.

The different effects of such halides have been investigated on several organic compounds, in order to stress their different way of action, as will be discussed below.

\section{CHLORIDE AND BROMIDE}

The influence of chloride and bromide has been studied on $\mathrm{CHCl}_{3}$ and $\mathrm{CCl}_{4}$ degradation rate. The phototransformation of these chloromethanes on $\mathrm{TiO}_{2}$ proceeds through an oxidation/reduction sequence that brings to their dechlorination and mineralization $[17,18]$. The presence of $\mathrm{NaCl}\left(5 \times 10^{-2} \mathrm{M}\right)$ modifies the degradation rate of $\mathrm{CCl}_{4}$ (see Fig. 1). The degradation rate is significatively decreased, and also 


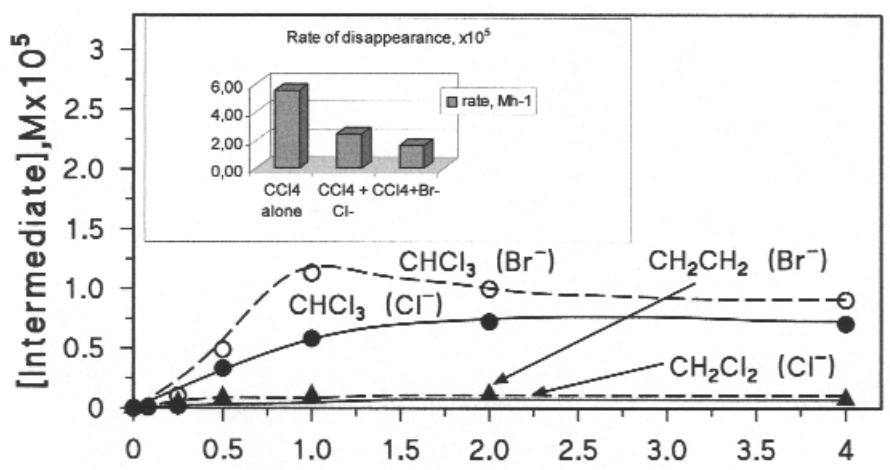

Fig. 1 Photocatalytic transformation of $\mathrm{CCl}_{4}\left(10 \mathrm{mgL}^{-1}\right)$ on $\mathrm{TiO}_{2} 200 \mathrm{mgL}^{-1}$ after addition of $\mathrm{NaCl}$ (or $\mathrm{KBr}$ ) $0.05 \mathrm{M}$ at $\mathrm{pH}$ 5. Intermediates evolution both with $\mathrm{Cl}^{-}$(continued line) and $\mathrm{Br}^{-}$(dotted lines). Inset: rate of disappearance of $\mathrm{CCl}_{4}$ with or without halide.

the intermediates evolution is influenced (i.e., $\mathrm{CHCl}_{3}$ is formed in larger amount [18]). The main reactions involved in the one-electron oxidation of halides lead to a very fast formation of an adsorbed $\mathrm{Cl}$. followed by formation of $\mathrm{Cl}_{2}{ }^{-}$(through reaction with $\mathrm{Cl}^{-}$).

The electron recapture by adsorbed $\mathrm{Cl}$. and $\mathrm{Cl}_{2}{ }^{-}$may follow the same mechanism in competition with other electron-capturing species [19], while the disproportion reaction $\left(2 \mathrm{Cl}_{2} .^{-} \rightarrow \mathrm{Cl}_{2}+2 \mathrm{Cl}^{-}\right)$ seems to play only a minor role.

The photogenerated holes are scavenged by chloride ions, so that they should increase the electron availability and the degradation rate of $\mathrm{CCl}_{4}$. The experimentally observed decrease suggests that the reaction:

$$
\cdot \mathrm{CCl}_{3}+\cdot \mathrm{Cl} \rightarrow \mathrm{CCl}_{4}
$$

and the electron recapture by adsorbed $\mathrm{Cl} \cdot$ and $\mathrm{Cl}_{2}{ }_{2}{ }^{-}$overcome the scavenging effects of reaction 21 .

The addition of $\mathrm{KBr}\left(5 \times 10^{-2} \mathrm{M}\right)$ induces a similar decrease in the degradation rate of $\mathrm{CCl}_{4}$ (see Fig. 1). A process similar to the one described with chloride occurs. Since bromide is an even better hole scavenging than $\mathrm{Cl}^{-}$, the hole-scavenging effects are balanced by the electron-scavenging effect of $\cdot \mathrm{Br}\left(\right.$ or $\left.\mathrm{Br}_{2} \cdot{ }^{-}\right)$:

$\mathrm{Br}_{2}{ }^{-}+\mathrm{e}-\rightarrow 2 \mathrm{Br}^{-}$

By analogy with $\mathrm{Cl}^{-}$, if $\mathrm{Br}$ radical is formed, mixed halomethanes should be originated according to reactions 27 and 28 :

$$
\begin{aligned}
& \cdot \mathrm{CCl}_{3}+\mathrm{Br} \cdot \rightarrow \mathrm{CBrCl}_{3} \\
& : \mathrm{CCl}_{2}+\mathrm{Br}^{-}+\mathrm{H}^{+} \rightarrow \mathrm{CHBrCl}_{2}
\end{aligned}
$$

Small quantities of $\mathrm{CBrCl}_{3}$ and traces of $\mathrm{CHCl}_{2} \mathrm{Br}$ have been experimentally detected, so confirming the occurrence of reactions 27 and 28.

The influence of chloride and bromide on chloroform degradation rate is represented in Fig. 2. In the presence of chloride, $\mathrm{CHCl}_{3}$ can be concurrently reduced by $\mathrm{e}_{\mathrm{CB}}^{-}$(formation of $\cdot \mathrm{CHCl}_{2}$ ) or oxidized [21] according to reactions 29 and 30:

$$
\begin{aligned}
& \mathrm{CHCl}_{3}+\mathrm{h}^{+}{ }_{\mathrm{VB}}\left(\text { or } \mathrm{OH}_{\text {ads }}\right) \rightarrow \cdot \mathrm{CCl}_{3}+\mathrm{H}^{+} \\
& \mathrm{CHCl}_{3}+\cdot \mathrm{Cl} \rightarrow \cdot \mathrm{CCl}_{3}+\mathrm{H}^{+}+\mathrm{Cl}^{-}
\end{aligned}
$$




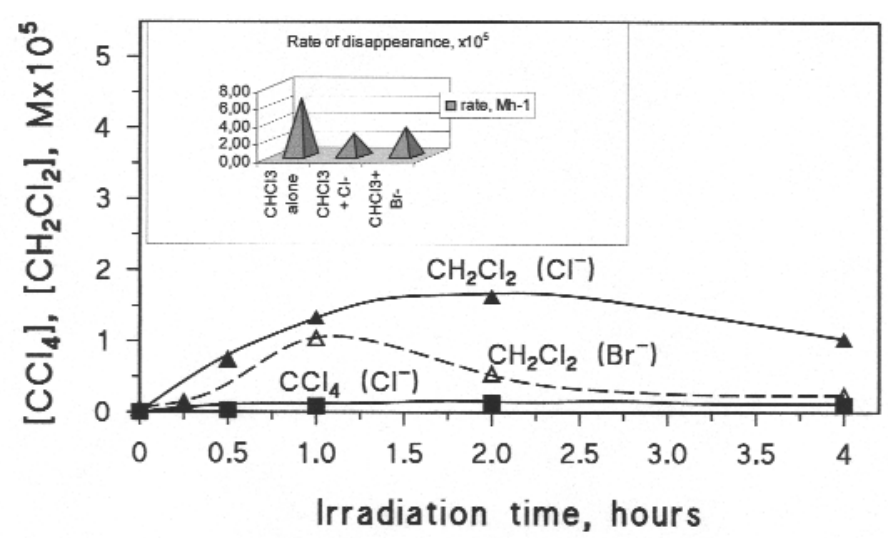

Fig. 2 Photocatalytic transformation of $\mathrm{CHCl}_{3}\left(10 \mathrm{mgL}^{-1}\right)$ on $\mathrm{TiO}_{2} 200 \mathrm{mgL}^{-1}$ after addition of $\mathrm{NaCl}$ (or $\mathrm{KBr}$ ) $0.05 \mathrm{M}$ at $\mathrm{pH}$ 5. Intermediates evolution both with $\mathrm{Cl}^{-}$(continued line) and $\mathrm{Br}^{-}$(dotted lines). Inset: rate of disappearance of $\mathrm{CHCl}_{3}$ with or without halide.

The contribution of reductive pathway should be decreased either by reaction 31 (giving a null effect when combined with reactions 29 and 30):

$$
\cdot \mathrm{CHCl}_{2}+\cdot \mathrm{Cl} \rightarrow \mathrm{CHCl}_{3}
$$

or by electron scavenging through the reduction of chlorine radical according to eq. 23 . The formation of chlorine radical is evidenced by the appreciable production of $\mathrm{CCl}_{4}$ [22], as shown in Fig. 2, according to reaction 25 .

The degradation rate of chloroform in presence of $\mathrm{Br}^{-}$decreases slightly less than in the presence of chloride (Fig. 2). Traces of $\mathrm{CBrCl}_{3}$ are observed [18] and are generated through a pathway similar to the one followed in the presence of chloride. From such experiments, it may be concluded that a photocatalytic process in presence of chloride or bromide may originate heavily halogenated chloromethanes.

It is noteworthy that no significant effect of $\mathrm{Cl}^{-}$and $\mathrm{Br}^{-}$is observed at $\mathrm{pH} 11$. Above $\mathrm{pH}_{\mathrm{PZC}}$ [20], no adsorption of anions on $\mathrm{TiO}_{2}$ occurs, and, as a consequence, the formation of $\mathrm{X} \cdot$ is strongly inhibited, in agreement with the considerations previously reported.

\section{Effect of fluoride}

Mechanistic details of photocatalytic process (bound vs. free hydroxyl, direct electron transfer to the hole, back reaction, adsorption at the catalyst surface, kinetic model, etc.) are still unravelled and could shed light on the parameters affecting the quantum efficiency of the process.

Recent studies on the effect of fluoride added to $\mathrm{TiO}_{2}$ suspensions have contributed to insight on the photocatalytic events $[23,24]$.

\section{Surficial charge and distribution on $\mathrm{TiO}_{2}$ and $\mathrm{TiO}_{2} / \mathrm{F}$}

Adsorption experiments and XPS measurement [25] indicate that fluoride ions strongly interact with $\mathrm{TiO}_{2}$. A variety of anionic species in aqueous solution undergo inner-sphere ligand substitution reaction with the surface hydroxyl.

In presence of fluoride, it is supposed a simple exchange equilibrium as indicated below, where $\mathrm{A}$ and $\mathrm{B}$ indicate the acidic and basic sites, respectively. 


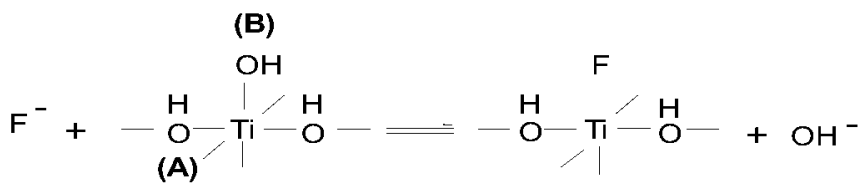

Fluoride ion replaces the basic hydroxyls, indicated as B, (as confirmed by IR and XPS spectroscopy [25,26]) according to the above reaction for which an equilibrium constant $\mathrm{k}_{1}=8 \times 10^{-7}$ has been reported [27], and coordinates the surface-bound titanium atoms directly.

Considering the above equilibrium and the number balance for surface sites $\mathrm{C}_{\mathrm{S}}=\left[\mathrm{TiOH}_{2}^{+}\right]+$ $[\mathrm{TiOH}]+\left[\mathrm{TiO}^{-}\right]+[\mathrm{TiF}]$ (calculated according to eqs. 1 and 2), the surface coverage in the dark can be calculated [23]. It is worth mentioning that for $0.01 \mathrm{M} \mathrm{F}^{-}$and $\mathrm{pH} 3.6$ the surface coverage by fluoride ions was maximum [23]. For this reason, the experiments described below have been performed at $\mathrm{pH}$ 3.6. The fluoride still remains the prevalent species at this $\mathrm{pH}$.

The fluoride displacement of the surficial hydroxyl group of titanium dioxide in aqueous solution has been shown to introduce relevant modifications in the properties of titanium dioxide, either in the physical aspects or in the photocatalytic properties. A milky suspension of naked Degussa P25 is stable for days, whereas after addition of $0.01 \mathrm{M} \mathrm{NaF}$ (pH 3.6 with HF) the suspension stability changes and settles down in $30 \mathrm{~min}$. There is also an enlarged region of small surface charge, extended from pH 3 to 6 (see Fig. 3). This may be important particularly for charged substrates or intermediates and for the possibility of interfacial electron transfer.

The low value of the surface charge in the $\mathrm{pH}$ range 3-6 causes coagulation of the particles. This could modify the reactive surface area [28] and the scattering of incident photons. The measurements of electrophoretic mobilities [29] confirm the modest charge of the colloidal particles of $\mathrm{TiO}_{2} / \mathrm{F}$ in the range 4-6, thus explaining the flocculation observed in the presence of $0.01 \mathrm{M}$ fluoride in this $\mathrm{pH}$ domain.

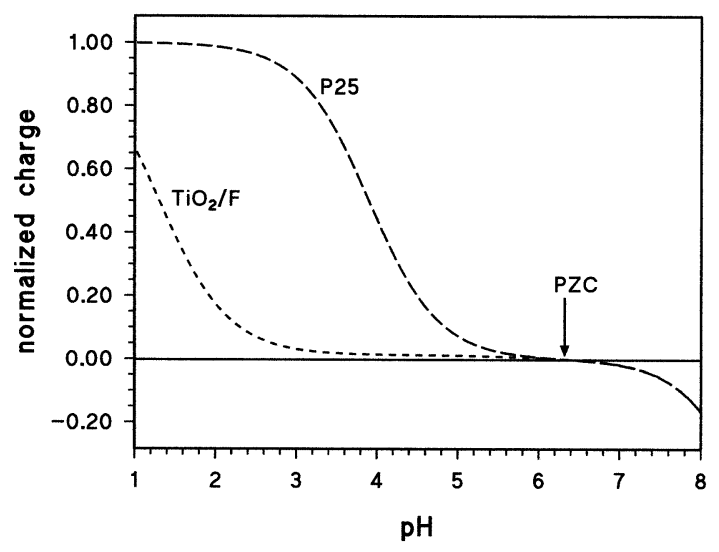

Fig. 3 Surficial distribution and surface charge for $\mathrm{TiO}_{2}$ Degussa $\mathrm{P} 25$ and $\mathrm{TiO}_{2} / \mathrm{F}$ as a function of $\mathrm{pH}$.

\section{Influence on phenol degradation}

Phenol photocatalytic degradation has been extensively investigated $[8,30]$. However, the fluoride displacement of the surficial hydroxyl groups of $\mathrm{TiO}_{2}$ in aqueous solution has been shown to introduce relevant modifications in the kinetics and mechanism of the photocatalytic degradation of phenol. We will focus on the modifications induced in the degradation rates, while the mechanistic details have been fully discussed in a previous paper [23]. 
Phenol $2 \times 10^{-4} \mathrm{M}$ has been irradiated both adopting $\mathrm{TiO}_{2}$ naked and fluorinated. The rate of disappearance of phenol alone and in presence of different concentrations of fluoride anions is represented in Table 1, from which emerges that on $\mathrm{TiO}_{2}$ fluorinated an increase in the rate of disappearance occurs. The reaction rate was strongly dependent on the surface coverage by $\equiv \mathrm{TiF}$ species (concentration of fluoride ions and $\mathrm{pH}$ ). In fact, the degradation rate increases while increasing the fluoride concentration (rate passes from $0.098 \mathrm{~min}^{-1}$ with $\mathrm{F}^{-} 1 \times 10^{-3} \mathrm{M}$ to $0.15 \mathrm{~min}^{-1}$ with $\mathrm{F}^{-} 0.01 \mathrm{M}$ ) and is maximum for $\mathrm{pH}$ ranging from 3.6 to 5 , thus reflecting the TiF distribution.

Table 1 Observed rate constant of disappearance of phenol $\left(2 \times 10^{-4} \mathrm{M}\right)$ on $\mathrm{TiO}_{2} 0.1 \mathrm{gL}^{-1}$ as a function of $\mathrm{pH}$ and fluoride concentration.

\begin{tabular}{lcccc}
\hline Rate, $\mathrm{min}^{-1}$ & $0 \mathrm{~F}^{-}$ & $1 \times 10^{-3} \mathrm{M} \mathrm{F}^{-}$ & $3 \times 10^{-3} \mathrm{M} \mathrm{F}^{-}$ & $1 \times 10^{-2} \mathrm{M} \mathrm{F}^{-}$ \\
\hline pH 2.5 & - & - & - & 0.09 \\
pH 3.6 & 0.056 & 0.098 & 0.12 & 0.15 \\
pH 4 & - & - & - & 0.17 \\
pH 5 & - & - & - & 0.17 \\
pH 6 & - & - & - & $\mathbf{0 . 1 1}$ \\
\hline
\end{tabular}

The variation of the degradation rate due to the presence of fluoride anions could be attributed to several causes. The diminution of $\equiv \mathrm{TiOH}$ as increasing $[\mathrm{F}]$ will decrease the ability to trap the holes as $\equiv \mathrm{TiO} \cdot(\cdot \mathrm{OH}$ ads) as expected according to reaction 5. Because reaction 19 is not allowed for $\mathrm{X}=\mathrm{F}$, this will increase $\mathrm{h}^{+}$VB availability and consequently affect either the direct electron transfer to the organic electron donors or recombination of the charge carriers. In addition, the depletion of $\equiv \mathrm{TiOH}$ will inhibit the formation of surficial peroxide. Moreover, fluoride anion is well known as the inhibitor of the complex formation between Ti(IV) and peroxide[31].

The displacement of $\mathrm{OH}^{-}$by $\mathrm{F}^{-}$changes the adsorption and the surface interactions. In particular, for organic compounds that interact with $-\mathrm{OH}$ groups, the extent of this interaction is largely modified, as is reported elsewhere for cathecol [32,33]. Also, the rate of electron scavenging by $\mathrm{O}_{2}$ and of superoxide formation will be influenced.

The shift of the potential of the valence and conduction band may be induced by fluoride substitution of $\mathrm{OH}$ [34]. However, controversial was the role of direct electron transfer to the hole vs. $\mathrm{OH}$ radical oxidation of organic compounds. Hole oxidation has been suggested for compounds lacking abstractable hydrogen and for some aromatic compounds, as evidenced by diffused reflectance flash photolysis [35].

Different oxidant species might be present in the photocatalytic system; the hole, the surfacetrapped hole (TiO), and the free $\cdot \mathrm{OH}$ radical. The bulk holes, formed upon photon adsorption, migrate to the surface where they can interact with surficial water or hydroxyl groups to form $\cdot \mathrm{OH}$ or $\equiv \mathrm{TiO}$, respectively, or be trapped as subsurface holes. As trapped, the hole may interact with organic compounds through direct electron transfer both through -O- or -Ti- species.

Their presence and their role in the oxidation depend both on photocatalyst surface characteristics and solution composition. Some clarification has come from experiments performed in the presence of alcohols, which can be used as diagnostic tools since suppressing the $\mathrm{OH}$ radical-mediated process.

Considering the effect of several alcohols on the kinetics of degradation of phenol both on naked $\mathrm{TiO}_{2}$ and $\mathrm{TiO}_{2} / \mathrm{F}$, the surface coverage by fluoride ions impedes the surface trapping of photogenerated holes (as $\equiv \mathrm{TiO}$ ) ) with the possibility to discriminate, by comparison with naked $\mathrm{TiO}_{2}$, the surfacemediated pathway from that taking place via free $\cdot \mathrm{OH}$ radicals. A quantitative study of this process is reported elsewhere [24].

On naked $\mathrm{TiO}_{2}$, increasing evidences are given for a surface mechanism. The comparison of the kinetics of the photocatalytic transformation of phenol on naked $\mathrm{TiO}_{2}$ in the presence of different alco- 
hols suggests that its oxidation proceeds either through the reaction with surficial bound hydroxyl and via a direct interaction with the holes. At large alcohol concentration, the rate mediated by surfacetrapped hydroxyl radicals is very low; the only possible pathway is through direct electron transfer.

On $\mathrm{TiO}_{2} / \mathrm{F}$ the effect of alcohol inhibition is pronounced (see Table 2). In the absence of any scavenger with phenol $2 \times 10^{-4} \mathrm{M}$, the rate constant is $0.15 \mathrm{~min}^{-1}$, which decreases to 0.057 (with $0.01 \mathrm{M}$ tert-butanol) and to $6.7 \times 10^{-3} \mathrm{~min}^{-1}$ (with $0.1 \mathrm{M}$ tert-butanol). On fluorinated $\mathrm{TiO}_{2}$, the reaction proceeds almost entirely via homogeneous hydroxyl radicals owing to the unavailability of surface-bound hydroxyl in the presence of fluoride.

Table 2 Observed rate constant of disappearance of phenol $\left(2 \times 10^{-4} \mathrm{M}\right)$ on $\mathrm{TiO}_{2} 0.1 \mathrm{gL}^{-1}$ naked or $\mathrm{TiO}_{2} / \mathrm{F} 0.01 \mathrm{M}$ as a function alcohols concentration.

\begin{tabular}{lccc}
\hline Rate, $\mathrm{min}^{-1}$ & [alcohol], $\mathrm{M}$ & t-butanol & 2-propanol \\
\hline $\mathbf{T i O}_{2}$ naked & 0 & $5.6 \times 10^{-2}$ & $5.6 \times 10^{-2}$ \\
& 0.01 & $2.6 \times 10^{-2}$ & $1.9 \times 10^{-2}$ \\
& 0.02 & $1.4 \times 10^{-2}$ & $1.1 \times 10^{-2}$ \\
$\mathbf{T i O}_{\mathbf{2}} \mathbf{F}$ & 0.1 & $7.8 \times 10^{-3}$ & $4.5 \times 10^{-3}$ \\
& 0 & 0.15 & 0.15 \\
& 0.01 & $5.7 \times 10^{-2}$ & $3.2 \times 10^{-2}$ \\
& 0.02 & $2.8 \times 10^{-2}$ & $1.8 \times 10^{-2}$ \\
& 0.1 & $6.7 \times 10^{-3}$ & $3.8 \times 10^{-3}$ \\
\hline
\end{tabular}

\section{CONCLUSIONS}

The presence of chloride and bromide on the photocatalytic degradation of $\mathrm{CHCl}_{3}$ leads to the formation of more halogenated methanes. The scavenging mechanism of such halides is the competition with organic compounds for the photogenerated oxidative species rather than a mere site occupation.

The most important conclusions in the presence of fluoride are related to the substitution of the hydroxyl groups by fluoride on the $\mathrm{TiO}_{2}$ surface in the range $\mathrm{pH} 2-6$. The primary aim of this work was to achieve evaluation of the extent of the different pathways operating in the photocatalytic transformation of phenol chosen as a model organic molecule. The degradation rate of phenol increases as a function of the fluoride concentration, and its dependence on $\mathrm{pH}$ reflects that of the surficial $\equiv \mathrm{TiF}$ distribution. This rate increase can be explained by the major extent of homogeneous $\mathrm{OH}$ reaction and direct electron transfer from the aromatic ring to the hole and by a decrease in the back reaction extent.

Alcohols have been used as diagnostic tools for suppressing the $\mathrm{OH}$ radical-mediated process. On naked $\mathrm{TiO}_{2}$, the mechanism may involve direct electron transfer and/or reaction with the bound surficial hydroxyl. For phenol, which is poorly interacting with the surface, the last mechanism is prevailing. Only this path is efficiently inhibited by alcohols such as tert-butyl alcohol and 2-propanol. It may be concluded that on $\mathrm{TiO}_{2} / \mathrm{F}$, the phenol degradation proceeds almost entirely through homogeneous $\mathrm{OH}$ radical reaction.

\section{REFERENCES}

1. C. Minero, F. Catozzo, E. Pelizzetti. Langmuir 8, 481-486 (1992).

2. W. Stumm and J. J. Morgan. Aquatic Chemistry, Wiley, New York (1996).

3. C. Kormann, D. W. Bahnemann, M. R. Hoffmann. Environ. Sci. Technol. 25, 494-500 (1991).

4. M. Abdullah, J. K. C. Low, R. W. Matthews. J. Phys. Chem. 94, 6820-6825 (1990).

5. J. C. D'Oliveira, C. Guillard, C.Maillard, P. Pichat. J. Environ. Sci. Health A28, 941-956 (1993).

6. N. Jaffrezic-Renault, P. Pichat, A. Foissy, R. Mercier. J. Phys. Chem. 90, 2733 (1986). 
7. V. Augugliaro, L. Palmisano, A. Sclafani, C. Minero, E. Pelizzetti. Toxicol. Environ. Chem. 16, 89 (1988).

8. J. N. Isralachvili. Intermolecular and Surface Forces, $2^{\text {nd }}$ ed., p. 12, Academic, San Diego (1992).

9. G. K-C. Low, S. R. McEvoy, R. W. Matthews. Environ. Sci. Technol. 24, 460 (1991).

10. D. Bahnemann, J. Cunnigham, M. A. Fox, E. Pelizzetti, P. Pichat, N. Serpone. In Aquatic and Surface Photochemistry, G. R. Helz, R. G. Zepp, D. G. Crosby (Eds.), pp. 275-278, Lewis, Boca Raton, FL (1994).

11. A. Fujishima, T. Inoue, K. Honda. J. Am. Chem. Soc. 101, 5582 (1979).

12. A. Henglein. Ber. Bunsenges. Phys. Chem. 86, 241 (1982).

13. J. Moser and M. Graetzel. Helv. Chem. Acta 65, 1436 (1982).

14. P. Wardman. J. Phys. Chem. Ref. Data 18, 1637 (1989).

15. H. P. J. Bohem. J.Chem. Soc., Faraday Discuss. 66, 264-275 (1972).

16. D. M. Stanbury. Adv. Inorg. Chem. 33, 69-138 (1989).

17. P. Calza, C. Minero, E. Pelizzetti. Environ. Sci. Technol. 31, 2198-2203 (1997).

18. P. Calza, C. Minero, E. Pelizzetti. J. Chem. Soc., Faraday Trans. 93 (21), 3765-3771 (1997).

19. D. J. Fitzmaurice, M. Eschle, H. Frei, J. Moser. J. Phys. Chem. 97, 3806, (1993).

20. J. Augustynski. Struct. Bonding, Berlin, 69, 1 (1988).

21. W. Choi and M. R. Hoffmann. Environ. Sci. Technol. 29, 1646 (1995).

22. C. Minero, V. Maurino, P. Calza, E. Pelizzetti. New J. Chem. 21, 841-842 (1997).

23. C. Minero, G. Mariella, V. Maurino, E. Pelizzetti. Langmuir, 16 (6), 2632-2641 (2000).

24. C. Minero, G. Mariella, V. Maurino, D. Vione, E. Pelizzetti. Langmuir 16, 8964-8972 (2000).

25. J. Sanchez and J. Augustynski. J. Electroanal. Chem. 103, 423-426 (1979).

26. J. A. R. Z. Van Veen. Phys. Chem. 162, 215-229 (1989).

27. M. Herrmann, U. Kaluza, H. P. Bohem. Z. Anorg. Chem. 372, 308-313 (1970).

28. S. Karmakar and H. L. Greene. J. Catal. 151, 394-406 (1995).

29. C. Minero, V. Maurino, P. Bernardez-Cordero, P. Calza, T. Picatonotto, D. Vione, E. Pelizzetti. In preparation.

30. K. Okamoto, Y. Yamamoto, H. Tanaka, M. Tanaka, A. Itaka. Bull. Chem. Soc. Jpn. 58, 2015-2022 (1985).

31. J. Stauff and H. Huster. J. Z. Phys. Chem., Frankfurt 55, 39-52 (1967).

32. G. Munuera, J. A. Navio, V. Rives-Arnaud. In $4^{\text {th }}$ International Conference on Photochemical Conversion and Storage of Solar Energy, J. Rabani (Ed.), pp. 141-143, Hebrew University, Jerusalem (1982).

33. G. Munuera, A. R. Gonzales-Elipe, V. Rives-Arnaud, J. A. Navio, P. Malet, J. Soria, J. C. Conesa, J. Sanz. In Studies in Surface Science and Catalysis, M. Che and G. C. Bond (Eds.), Elsevier, Amsterdam, 21, 113-125 (1985).

34. C. M. Wang and T. E. Mallouk. J. Phys. Chem. 94, 4276-4280 (1990).

35. R. B. Draper and M. A. Fox. Langmuir 6, 1396-1401 (1990). 